\title{
BAFF: U na citoquina reguladora de linfocitos B implicada en autoinmunidad y cáncer linfoide
}

\author{
Lilian I Reyes $\mathrm{S}^{\mathrm{a}}$, Francisca León $\mathrm{B}^{\mathrm{b}}$, M Fernanda Rozas $\mathrm{V}^{\mathrm{b}}$, \\ Patricia González Ja, Rodrigo Naves Pc.
}

\section{BAFF: A regulatory cytokine of $B$ lymphocytes involved in autoimmunity and lymphoid cancer}

BAFF (B cell activating factor belonging to the TNF family) is a cytokine implicated in the survival and maturation of peripheral $B$ lymphocytes and $T$ and $B$ cell activation. BAFF binds to three different receptors: TACI, BCMA and BAFF-R, whose expression is restricted to $\mathrm{B}$ and $\mathrm{T}$ lymphocytes. BAFF and BAFF-R-deficient mice show a dramatic loss of peripheral B lymphocytes and a severely reduced immune response. In contrast, an enhanced BAFF expression leads to B cell hyperplasia and autoimmunity in mice. In vivo, administration of soluble decoy receptors for BAFF effectively decreases disease progression in various autoimmune mouse models. These evidences render BAFF as a potentially new therapeutic target. Elevated BAFF levels have been detected in the serum of patients with autoimmune diseases, such as Systemic Lupus Erythematosus, rheumatoid arthitis, Sjögren's syndrome, lymphoid cancers and HIV infection. In addition to BAFF receptors, malignant B cells abnormally express BAFF, which attenuates apoptosis through both autocrine and paracrine pathways. The data suggest that an increase in the expression of BAFF induces an enhanced B and T cell activation and the survival of pathologically active B cells. In this article, we review and discuss the participation of BAFF and its receptors in the immune response and its involvement in immunodeficiency, autoimmunity, infections and lymphoid cancers as well as the currently investigated therapies using BAFF antagonists in the treatment of these diseases (Rev Méd Chile 2006; 134: 1175-84).

(Key words: Autoimmunity; B cell activating factors; Cytokines)

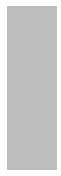

Recibido el 9 de septiembre, 2005. Aceptado el 26 de enero, 2006.

Instituto de Ciencias, Facultad de Medicina, Clínica Alemana Universidad del Desarrollo

a Bioquímico

b Estudiante de Medicina

c Biólogo, PhD en Biología Celular y Molecular

Correspondencia a: Dr. Rodrigo Naves. Instituto de Ciencias, Facultad de Medicina, Clínica Alemana Universidad del Desarrollo. Av. Las Condes 12.438, Lo Barnechea. Fono: 299 9246. Fax: 299 9306. E-mail: mavesp@udd.cl 
L as citoquinas son proteínas que actúan como _un sistema de señales entre las células, permitiendo una respuesta inmune integrada. A través de su unión a receptores presentes en la superficie de las células blanco, las citoquinas regulan importantes funciones biológicas, tales como proliferación, activación, sobrevida, muerte y diferenciación celular1. Recientemente, se ha identificado a BAFF (factor activador de linfocitos B perteneciente a la familia TNF), también conocido como BLyS, THANK, TAL-1 o zTNF4, como una citoquina con importantes efectos moduladores de la respuesta inmune ${ }^{2-4}$. Varios trabajos han determinado que la alteración en la expresión de BAFF está relacionada con el desarrollo de autoinmunidad y cáncer linfoide, y los antecedentes descritos en la literatura permiten considerar a BAFF como un potencial blanco terapéutico. A continuación revisamos la información existente acerca de la función de BAFF, la regulación de su expresión, sus receptores celulares, su implicación en patologías infecciosas, inmunológicas y neoplásicas, así como la utilización de una terapia biológica dirigida contra BAFF en el tratamiento de estas enfermedades.

\section{FunCIÓN BIOLÓGICA DE BAFF}

El desarrollo de linfocitos $B$ es un proceso temporal y espacialmente regulado a través de eventos que comienzan en la médula ósea, donde progenitores linfoides se diferencian a linfocitos $B$. Después de un proceso de selección, estas células migran hacia el bazo, donde los linfocitos B pasan por varios estados intermedios de maduración llamados estados de transición de tipo 1 (T1), de tipo 2 (T2) y de tipo 3 (T3), antes de lograr una madurez completa ${ }^{5,6}$. A lo largo de estas etapas, las células son sometidas a un proceso de selección periférica negativa, en el cual linfocitos B con el potencial para montar una respuesta autoinmune son eliminados a través del mecanismo de muerte celular programada o apoptosis. Estudios realizados tanto in vitro como in vivo han demostrado que BAFF regula la sobrevida de linfocitos B T2 a través de la activación de factores anti-apoptóticos de la familia de proteínas Bcl$2^{2,7,8}$. Además, recientemente se ha observado que BAFF también actúa como un co-estimulador de la proliferación de los linfocitos $\mathrm{B}$ y $\mathrm{T}^{9,10}$.
El análisis de la manipulación de la expresión de BAFF en animales de experimentación llevó a concluir que una alteración en la expresión de BAFF provoca graves consecuencias en la homeostasis de la respuesta inmune (Figura 1). Por un lado, ratones knock out para la expresión de BAFF, es decir, ratones manipulados genéticamente para que no expresen BAFF, presentan una disminución en el número de linfocitos B T2 y maduros periféricos, una reducción en los niveles de inmunoglobulinas totales y una respuesta inmune deficiente frente a un desafío inmunológico ${ }^{11}$ (Tabla 1). Por otro lado, el estudio de ratones normales inyectados con BAFF recombinante ${ }^{3}$ y de ratones transgénicos que sobreexpresan $\mathrm{BAFF}^{2}$, reveló otros interesantes resultados. En estos ratones se observó una hiperplasia de linfocitos B maduros, esplenomegalia, aumento del número y tamaño de los centros germinales en ausencia de inmunización, aumento de células $\mathrm{B}$ plasmáticas en los órganos linfoides secundarios, hiperglobulinemia y manifestaciones autoinmunes tales como, aumento del factor reumatoide, depósitos de complejos inmunes en el riñón, proteinuria y altos niveles de anticuerpos anti-ADN de doble hebra (Tabla 1). Muchas de estas manifestaciones autoinmunes son similares a las que exhiben pacientes con lupus enitematoso sistémico y artritis reumatoide. Estos estudios sugieren que la sobreexpresión de BAFF permitina un aumento anormal en la sobrevida y maduración de linfocitos B periféricos, vulnerándose los mecanismos de selección negativa y facilitando la circulación de linfocitos B autorreactivos, los que eventualmente darían inicio al desarmollo de una respuesta autoinmune.

\section{EXPRESIÓN DE BAFF}

BAFF se expresa como una proteína de transmembrana en la superficie celular o en forma soluble, producto del corte proteolítico extracelular de la proteína de transmembrana mediado por una proteasa del tipo furina ${ }^{4,12-14}$ (Figura 1). Inicialmente, se describió que BAFF era expresado y secretado por células de origen mieloide tales como monocitos, macrófagos y células dendríticas ${ }^{4,13}$. Sin embargo, trabajos recientes han demostrado que BAFF también es expresado por neutrófilos acti$\operatorname{vados}^{14}$, fibroblastos sinoviales ${ }^{15}$, astrocitos ${ }^{16}$, cé- 


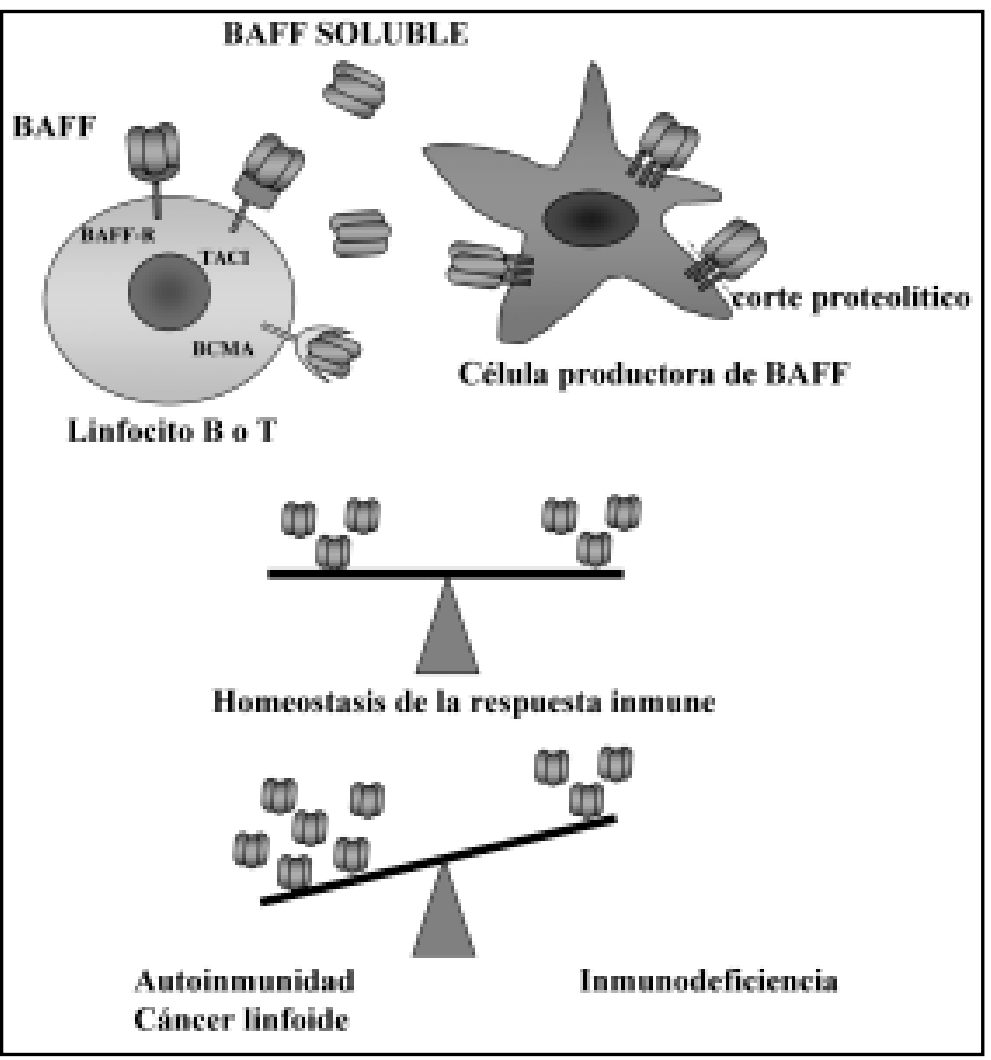

Figura 1. Expresión y función de BAFF. BAFF (Factor Activador de Linfocitos B perteneciente a la familia TNF), expresado como una proteína de transmembrana 0 en forma soluble, interactúa con los receptores BAFF-R (BAFF Receptor), TACI (Transmembrane Activator and CAML Interactor) $\mathrm{y}$ BCMA (B Cell Maturation protein A) expresados por linfocitos B y T. BAFF cumple un importante papel en la homeostasis de la respuesta inmune regulando la sobrevida y maduración de linfocitos B y como un co-estimulador de la proliferación de linfocitos B y T. Un desequilibrio en la expresión de BAFF conduce a una drástica alteración en la respuesta inmune. Así, una disminución en la expresión de BAFF produce una respuesta inmune deficiente, mientras que un aumento en su expresión está asociado con enfermedades autoinmunes y cáncer linfoide.

Tabla 1. Fenotipo de ratones con expresión anormal de BAFF y sus receptores

\begin{tabular}{|c|c|c|}
\hline Ratón & Fenotipo & Referencias \\
\hline *BAFF transgénico & $\begin{array}{l}\text { Hiperplasia de células B; hiperglobulinemia; } \\
\text { esplenomegalia; producción de autoanticuerpos } \\
\text { (factor reumatoideo, anti-ADN); glomerulonefritis. }\end{array}$ & 2,3 \\
\hline$* * \mathrm{BAFF} \%$ & $\begin{array}{l}\text { Detención de la maduración de las células B } \\
\text { en el estado T1; títulos de anticuerpos disminuidos } \\
\text { (excepto Ig A); respuesta inmune deficiente. }\end{array}$ & 11 \\
\hline $\begin{array}{l}\text { Ratón A/WySnJ, mutante } \\
\text { natural para BAFF-R }\end{array}$ & $\begin{array}{l}\text { Detención de la maduración de células B en el estado T1; } \\
\text { títulos de anticuerpos disminuidos; respuesta inmune deficiente. }\end{array}$ & 26,30 \\
\hline$* * \mathrm{BCMA} \%$ & $\begin{array}{l}\text { Disminución en la sobrevida de células plasmáticas } \\
\text { de médula ósea de larga vida. }\end{array}$ & 34 \\
\hline *TACI $\%$ & $\begin{array}{l}\text { Aumento en el número de células B periféricas } \\
\text { y en la respuesta inmune dependiente de células } \mathrm{T} \text {. }\end{array}$ & $35,36,37$ \\
\hline
\end{tabular}

BAFF (B cell Activating Factor belonging to the TNF Family); BAFF-R (BAFF Receptor); BCMA (B Cell Maduration protein A); TACI (Transmembrane Activator and Calcium modulator and cyclophilin ligand Interactor). *Ratón que sobreexpresa BAFF. **Ratón deficiente en la expresión del gen indicado. 
lulas dendríticas foliculares ${ }^{17,18}$ y por células de órganos linfoides resistentes a radiación con características similares a células estromales ${ }^{19,20}$.

En relación a los factores que regulan la expresión de BAFF, se ha mostrado que tanto las citoquinas IL-10, interferones (IFN) alfa y gamma $^{2,21}$ como los lipopolisacáridos (LPS) bacterianos y peptidoglicán ${ }^{13,21,22}$ aumentan la expresión y secreción de BAFF en macrófagos, monocitos y células dendríticas. Además, la ligación de la molécula co-estimuladora CD40 y la combinación de IFN- $\gamma$ más G-CSF (factor estimulador de colonia de granulocito) estimulan la secreción de BAFF en células dendríticas y neutrófilos, respectivamente ${ }^{14,21}$. Por otro lado, células dendríticas de ratones deficientes en la expresión del factor de transcripción SOCS-1 (por su sigla en inglés Suppressor of Cytokine Signaling-1) expresan elevados niveles de BAFF, lo que sugiere que la expresión de BAFF es regulada negativamente por este factor ${ }^{23}$. Además, se ha descrito que IL-4 inhibe el aumento en la expresión de BAFF en monocitos estimulados con IL-10, pero no con IFN- $\gamma^{13}$ y que la activación con PMA/ionomicina regula negativamente la expresión de BAFF en monocitos y macrófagos ${ }^{24}$. Entonces, factores y moléculas que participan tanto en la respuesta inmune innata, como adquirida, tienen efectos sobre la expresión de BAFF. Sin embargo, se desconocen los mecanismos que regulan la expresión de esta citoquina, lo cual abre un nuevo campo de investigación en la búsqueda de posibles blancos que permitan controlar su expresión.

\section{RECEPTORES DE BAFF y PATOLOGÍAS}

BAFF es ligando de tres receptores: TACI (por su sigla en inglés Transmembrane Activator and Calcium modulator and cyclophilin ligand Interactor), BCMA (B Cell Maturation protein A) y BAFF-R (BAFF receptor), cuya expresión es bastante restringida. Mientras que BCMA, TACI y BAFF-R son expresados por linfocitos B, TACI y BAFF-R, son además expresados por linfocitos $\mathrm{T}$ activados ${ }^{10,12}$. Otra importante característica, es que BAFF-R es el único receptor que tiene como único ligando a $\mathrm{BAFF}^{10,25,26}$, mientras que BCMA y TACI también unen a otra citoquina de la familia TNF conocida como APRIL. Un antecedente inte- resante de destacar es que los tres receptores son expresados en distintas etapas de diferenciación de las células $\mathrm{B}^{12}$. BAFF-R es expresado predominantemente en linfocitos $\mathrm{B}$ vírgenes y de memoria, así como en linfocitos $\mathrm{T}$ efectores y de memoria ${ }^{10,18}$, mientras que BCMA y TACI son expresados principalmente en células $\mathrm{B}$ del centro germinal de órganos linfoides secundarios y células $B$ plasmáticas ${ }^{10,27-29}$. Según esto, los receptores de BAFF podrían mediar diferentes funciones. Las evidencias sugieren que la interacción BAFF-BAFF-R es clave en la regulación de la sobrevida de células $B$ periféricas y en el proceso de co-estimulación de linfocitos B y T. De hecho, ratones $\mathrm{A} / \mathrm{WySnJ}$, mutantes naturales para BAFF-R, presentan un fenotipo similar a los ratones deficientes en BAFF, es decir, una significativa reducción de linfocitos $\mathrm{B}$ maduros periféricos y una respuesta inmune deficiente ${ }^{26,30}$ (Tabla 1). Así mismo, se ha descrito que la expresión de BAFF$\mathrm{R}$ es determinante en la formación de los centros germinales ${ }^{31-33}$. En cambio, BCMA y TACI participarían en la fase efectora de la respuesta inmune humoral mediando la diferenciación de células $B$ plasmáticas. Con respecto a BCMA, se ha demostrado que la interacción BAFF-BCMA es esencial para la supervivencia de células plasmáticas de larga vida de la médula ósea ${ }^{34}$. A diferencia de lo observado en ratones mutantes para BAFF-R y BCMA, ratones deficientes para TACI desarrollaron manifestaciones autoinmunes caracterizadas por un elevado número de células $\mathrm{B}$ hiperrespondedoras, lo que sugiere que TACI podría actuar como un regulador negativo de la respuesta de linfocitos $\mathrm{B}^{35-37}$ (Tabla 1). Estos estudios muestran que el efecto neto de BAFF puede ser el resultado de un delicado equilibrio de señales transmitidas a través de sus tres receptores.

En relación a patologías asociadas a los receptores de BAFF, dos estudios recientes han mostrado una asociación entre diferentes mutaciones presentes en el gen que codifica para TACI y la enfermedad de Inmunodeficiencia Común Variable (ICV) ${ }^{38,39}$ (Tabla 2). Esta patología corresponde a un grupo heterogéneo de trastornos de la inmunidad, caracterizados por una defectuosa diferenciación de linfocitos B a células plasmáticas, deficiencia en la producción de anticuerpos y recurrentes infecciones bacterianas. En los trabajos mencionados se identificaron mutaciones homocigóticas y heterocigóticas 
Tabla 2. Asociación entre la expresión de BAFF, de sus receptores y patologías

\begin{tabular}{|c|c|c|}
\hline Patología & bservaciones & Referencias \\
\hline \multicolumn{3}{|l|}{ Autoinmunidad } \\
\hline Lupus eritematoso sistémico & $\begin{array}{l}\text { Modelos murinos y pacientes presentan niveles elevados } \\
\text { de BAFF, que se correlacionan directamente } \\
\text { con el número de criterios diagnósticos. }\end{array}$ & $42,46,47$ \\
\hline Artritis reumatoide & $\begin{array}{l}\text { Pacientes exhiben niveles elevados de BAFF en el suero } \\
\text { y en el líquido sinovial, los que se correlacionan } \\
\text { con la respuesta inmune inflamatoria. El tratamiento biológico } \\
\text { con el receptor soluble de BAFF tiene efectos profilácticos } \\
\text { y terapéuticos en un modelo murino de artritis reumatoide. }\end{array}$ & $15,43,44,45$ \\
\hline Síndrome de Sjögren & $\begin{array}{l}\text { Pacientes presentan niveles de BAFF aumentados en el suero } \\
\text { y en biopsias de tejido de glándula salival. }\end{array}$ & 48,49 \\
\hline \multicolumn{3}{|l|}{ Cáncer Linfoide } \\
\hline Linfoma no Hodgkin & $\begin{array}{l}\text { Pacientes presentan niveles elevados de BAFF en el suero. } \\
\text { Linfocitos B de estos pacientes expresan BAFF aberrantemente. }\end{array}$ & 50 \\
\hline $\begin{array}{l}\text { Leucemia linfocítica crónica } \\
\text { de linfocitos B }\end{array}$ & $\begin{array}{l}\text { Pacientes muestran niveles elevados de BAFF en el suero. } \\
\text { Linfocitos B de estos pacientes expresan BAFF aberrantemente, } \\
\text { el que protege a los linfocitos B de la apoptosis inducida } \\
\text { por drogas quimioterapéuticas. }\end{array}$ & 51 \\
\hline Mieloma múltiple & $\begin{array}{l}\text { Linfocitos B de estos pacientes expresan BAFF aberrantemente, } \\
\text { el que protege a los linfocitos B de la apoptosis inducida } \\
\text { por drogas quimioterapéuticas. }\end{array}$ & 52 \\
\hline \multicolumn{3}{|l|}{ Infecciones virales } \\
\hline $\begin{array}{l}\text { Virus de inmunodeficiencia } \\
\text { humana }\end{array}$ & $\begin{array}{l}\text { Suero de pacientes infectados presentan niveles aumentados } \\
\text { de BAFF, los que se correlacionan con el nivel } \\
\text { de autoanticuerpos y la progresión de la enfermedad. }\end{array}$ & 54,55 \\
\hline Virus de Epstein Barr & $\begin{array}{l}\text { Células B infectadas con el virus son inducidas a expresar BAFF } \\
\text { a través de un mecanismo dependiente de la proteína viral LMP1. }\end{array}$ & 56 \\
\hline \multicolumn{3}{|l|}{ Inmunodeficiencias } \\
\hline $\begin{array}{l}\text { Inmunodeficiencia común } \\
\text { variable }\end{array}$ & $\begin{array}{l}\text { Pacientes presentan mutaciones homocigóticas } \\
\text { y heterocigóticas en el gen de TACI y BAFF-R. }\end{array}$ & 38 \\
\hline
\end{tabular}

en el gen de TACI que afectan severamente su función o la expresión de su mARN y proteína en pacientes con ICV y deficiencia selectiva en IgA. Otro reporte, enviado a publicación, describe una deleción homocigótica en el gen de BAFF-R en una familia con ICV [mencionado en 40, 41].

\section{BAFF Y PATOLOGÍAS}

Autoinmunidad. Un conjunto de evidencias obtenidas tanto del estudio de diferentes modelos murinos de autoinmunidad como de estudios clínicos, han mostrado la importante participación de BAFF en el desarrollo de enfermedades autoinmunes (Tabla 2). Por un lado, ratones NZBWF1 y MRL-lpr/lpr, que desarrollan una patología similar al lupus eritematoso sistémico en humanos, exhiben niveles elevados de BAFF durante el inicio y la progresión de la enfermedad $^{42}$. El tratamiento de estos ratones con TACI-Ig, una proteína recombinante capaz de unir y neutralizar la actividad de BAFF soluble, inhibió el desarrollo de la proteinuria y prolongó la sobrevida de los animales ${ }^{42}$. Del mismo modo, la aplicación profiláctica de TACI-Ig en un modelo murino de artritis reumatoide inducida por colágeno II, provocó un significativo retraso en la aparición de la enfermedad, una destacada disminución de la 
inflamación y una supresión en la aparición de anticuerpos anti-colágeno ${ }^{43}$. Así mismo, la aplicación de TACI-Ig de un modo terapéutico, es decir, después de iniciada la enfermedad en los ratones con artritis reumatoide, provocó una inhibición en la progresión de la enfermedad, una ligera disminución en los niveles de anticuerpos anti-colágeno, una menor inflamación e hipertrofia del sinovio y no se detectó destrucción del cartílago ${ }^{43}$.

Por otro lado, estudios clínicos realizados en pacientes con enfermedades autoinmunes, tales como artritis reumatoide ${ }^{44,45}$, lupus eritematoso sistémico $^{46,47}$ y síndrome de Sjögren ${ }^{48,49}$, han determinado niveles elevados de BAFF en el suero de estos pacientes. Además, Tan y cols reportaron mayores niveles de BAFF en el fluido sinovial obtenido de articulaciones inflamadas de pacientes con artritis reumatoide que en pacientes con artritis no inflamatoria ${ }^{45}$. Este estudio clínico también demostró que los niveles de BAFF se correlacionan directamente con el número de monocitos, neutrófilos y linfocitos infiltrados en la articulación, mostrando una correlación positiva entre los niveles de BAFF y la respuesta inmune inflamatoria local ${ }^{45}$. Por lo tanto, estos antecedentes sugieren que la inflamación promueve la sobreexpresión de BAFF, probablemente a través de la activación de macrófagos, neutrófilos y células dendríticas. Sin embargo, es posible también que otros tipos celulares, que normalmente no expresan BAFF, sean inducidos a producirlo en respuesta a estímulos inflamatorios. Un ejemplo de ello, son los fibroblastos sinoviales obtenidos de las articulaciones inflamadas de pacientes con artritis reumatoide, en los cuales se ha demostrado expresión de BAFF en respuesta a citoquinas proinflamatorias ${ }^{15}$. Cabe destacar, que el estudio de un subgrupo de pacientes con lupus eritematoso sistémico que cumplían sólo con algunos criterios de diagnóstico para esta enfermedad presentaron niveles de BAFF circulante ligeramente más altos que los individuos controles, mientras que otro subgrupo de pacientes positivos para varios criterios de diagnóstico exhibieron niveles de BAFF significativamente más elevados ${ }^{46}$. Si bien el número de pacientes analizados fue pequeño, los autores sugieren que los niveles elevados de BAFF podrían representar un marcador del inicio de una alteración autoinmune.
Al igual que lo observado en los ratones transgénicos para BAFF, estos antecedentes indican que la producción excesiva de BAFF inducida por circunstancias patológicas tales como inflamación o pérdida de tolerancia inmunológica, promovería un aumento en la co-estimulación de linfocitos B y T. Además, BAFF permitiría la extensión en la sobrevida de células B autorreactivas responsables de la producción de autoanticuerpos implicados en la patogenia de varias enfermedades autoinmunes.

Linfomas. Debido a la capacidad de BAFF de aumentar la viabilidad de linfocitos B, varios trabajos han investigado su participación en la patogénesis de linfomas B (Tabla 2). Estos estudios han mostrado que el suero de pacientes con linfomas no-Hodgkin ${ }^{50}$, leucemia linfocítica crónica de linfocitos B (LC-B) ${ }^{51}$ y mieloma múltiple $(\mathrm{MM})^{52}$ presentan niveles elevados de BAFF. Además de expresar receptores para BAFF, se determinó que los linfocitos $\mathrm{B}$ de pacientes con LLC-B y MM también expresan BAFF, protegiendo a las células $B$ de estos pacientes de la apoptosis inducida por las drogas quimioterapéuticas flavopiridol y dexametasona ${ }^{51,52}$. En estos trabajos, se demostró que BAFF inhibió la apoptosis de linfocitos $\mathrm{B}$ a través de la activación de factores anti-apoptóticos tales como Bcl-2, Bcl- $\mathrm{x}_{\mathrm{L}}$ y Mcl-1 y de la inhibición del factor apoptótico

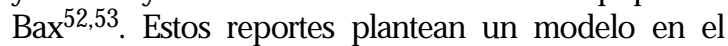
cual BAFF, a través de la interacción con sus receptores, puede inducir en forma autocrina la sobrevida de células malignas. Por lo tanto, la identificación y el estudio de los factores que modulen este proceso podnía tener importantes aplicaciones en el tratamiento de estas enfermedades.

Infecciones virales. El aumento en la expresión de BAFF también ha sido asociado con patologías infecciosas (Tabla 2). El análisis del suero de pacientes infectados con el virus de inmunodeficiencia humana (VIH) mostró niveles aumentados de BAFF, los que se comelacionaron positivamente con los niveles de autoanticuerpos ${ }^{54}$ y la progresión de la enfermedad ${ }^{55}$. Este aumento en los niveles circulantes de BAFF, podría ser el resultado de dos procesos, no necesariamente excluyentes. Por un lado, podńa ser parte de la respuesta inmune del huésped. En este caso, BAFF actuańa en la protección 
contra patógenos, posiblemente a través de su capacidad de reforzar las funciones efectoras de ciertas células inmunes, aumentando la producción de anticuerpos y la activación y sobrevida de células B y T efectoras. Por otro lado, es posible que el virus induzca una alteración en la expresión de BAFF y sus receptores como parte de un mecanismo de evasión de la respuesta inmune. En este sentido, Moir y col $^{56}$ determinaron que linfocitos $\mathrm{B}$ de los pacientes infectados con VIH presentan una disminución en la expresión de BAFF-R y una menor sobrevida en respuesta a BAFF, lo que podría explicar la mayor susceptibilidad a la apoptosis que exhiben linfocitos B de pacientes con $\mathrm{VIH}^{57,58}$ y la desmejorada respuesta inmune humoral que presentan los pacientes. Otro estudio, mostró que células B infectadas con el virus Epstein Barr (EBV) son inducidas a expresar BAFF a través de un mecanismo dependiente de la proteína viral LMP1 (por su sigla en inglés Latent Membrane Protein-1) ${ }^{59}$. Además de demostrar que ciertos virus pueden regular la expresión de BAFF, este último trabajo también relaciona a BAFF con el desarmollo de tumores, ya que varios cánceres linfoides, tal como el linfoma de Burkitt, pueden ser causados por la infección e inmortalización de células B humanas con el EBV60. En este caso, la inducción de la expresión de BAFF inducida por la infección viral podńa contribuir al desamollo del linfoma al aumentar la sobrevida de la célula huésped.

\section{TERAPIAS BIOLÓGICAS ANTI-BAFF}

La participación de BAFF en enfermedades autoinmunes ha impulsado a laboratorios farmacéuticos a desarrollar tres inhibidores de BAFF. Uno de ellos corresponde a un anticuerpo humanizado bloqueador de BAFF (Belimumab o LymphoStatB) ${ }^{61}$ y los otros dos a proteínas de fusión recombinantes bloqueadoras de los receptores TACI y BAFF- $\mathrm{R}^{62}$. Actualmente, LymphoStat-B se encuentran en la fase II de un estudio clínico para el tratamiento del lupus eritematoso sistémico y de la artritis reumatoide. Hasta ahora se ha reportado que la utilización de LymphoStat-B es segura y bien tolerada por los pacientes. Además, se ha probado que este tratamiento es biológicamente activo y que reduce significativamente los síntomas de la artritis reumatoide y el nivel de autoanticuerpos anti-ADN de doble hebra en pacientes con lupus eritematoso sistémico ${ }^{63}$.

\section{PeRSPECTIVAS}

Varios antecedentes relacionan un aumento en la expresión de BAFF con el desamollo de la artritis reumatoide. Sin embargo, no se ha establecido precisamente cuál senáa el papel que esta citoquina jugańa en este proceso. Uno de los cambios patológicos característicos de la artritis reumatoide es la formación del pannus, un tejido invasivo originado por hiperplasia de la membrana sinovial. El pannus, en conjunto con enzimas proteolíticas, causan la progresiva erosión del cartílago y del hueso subcondral. Mediante la utilización de un modelo murino de destrucción de cartílago in vivo se ha mostrado que el microambiente proinflamatorio de la articulación de los pacientes con artritis reumatoide induce a los fibroblastos de la membrana sinovial a desarmollar un comportamiento invasivo y un crecimiento descontrolado ${ }^{64-66}$. Si el crecimiento de estas células se debe a una proliferación exacerbada o a una inhibición en la apoptosis está actualmente en debate y se desconocen las señales que median este proceso ${ }^{67}$. En base a las evidencias que muestran que BAFF regula la sobrevida de ciertas células y que citoquinas proinflamatorias inducen la expresión de BAFF en fibroblastos sinoviales ${ }^{15}$, será interesante determinar si estas células expresan además los receptores para BAFF y el papel que desempeñan en la formación del pannus en pacientes con artritis reumatoide.

Dentro de un tiempo, los estudios clínicos en marcha indicarán si los antagonistas biológicos de BAFF tienen una aplicación efectiva en el tratamiento de enfermedades autoinmunes, lo que podnía extender su utilización a otras patologías tales como linfomas, leucemias o mielomas. Sin embargo, aún quedan muchas incógnitas por resolver. Prácticamente no se conoce nada acerca de los mecanismos de regulación de la expresión BAFF y sus receptores. Se desconoce la identidad, regulación y actividad de la enzima que procesa a BAFF de la membrana plasmática y si una alteración en la expresión de esta enzima tiene consecuencias patológicas. Claramente, el avance en estos temas permitirá comprender mejor la participación de BAFF en la respuesta inmune, determinar nuevos puntos de control y desarmollar nuevas estrategias terapéuticas. 


\section{REFERENCIAS}

1. Naves R, Bono MR. Citoquinas. En: Palomo I, FA, Sepúlveda C, Rosemblatt M, Vergara U. Fundamentos de Inmunología básica y clínica. Talca: Editorial Universidad de Talca, 2002; 211-37.

2. Mackay F, Woodcock SA, Lawton P, Ambrose C, BAETSChER M, SchNeIDER P ET AL. Mice transgenic for BAFF develop lymphocytic disorders along with autoimmune manifestations. J Exp Med 1999; 190: 1697-710.

3. Moore PA, Belvedere O, Orr A, Pieri K, Lafleur DW, Feng P ET AL. BLyS: member of the tumor necrosis factor family and B lymphocyte stimulator. Science 1999; 285: 260-3.

4. Schneider P, Mackay F, Steiner V, Hofmann K, BODMER JL, HOLer N ET AL. BAFF, a novel ligand of the tumor necrosis factor family, stimulates B cell growth. J Exp Med 1999; 189: 1747-56.

5 Aluman D, Lindsley RC, Demuth W, Rudd K, SHINTON S, HARDY RR. Resolution of three nonproliferative immature splenic B cell subsets reveals multiple selection points during peripheral B cell maturation. J Immunol 2001; 167: 6834-40.

6 LODER N. Tiny chromosome is rich in genes and medical promise. Nature 1999; 402: 448.

7 Batten M, Groom J, Cachero TG, Qian F, Schneider P, Tschopp J ET AL. BAFF mediates survival of peripheral immature B lymphocytes. J Exp Med 2000; 192: 1453-66.

8 Do RK, Hatada E, Lee H, Tourigny MR, Hilbert D, Chen-Kiang S. Attenuation of apoptosis underlies B lymphocyte stimulator enhancement of humoral immune response. J Exp Med 2000; 192: 95364.

9 Huard B, Arlettaz L, Ambrose C, Kindier V, Mauri D, ROosNeK E ET AL. BAFF production by antigenpresenting cells provides $\mathrm{T}$ cell co-stimulation. Int Immunol 2004; 16: 467-75.

10 Ng LG, Sutherland AP, Newton R, Qian F, Cachero TG, SсотT ML ET AL. B cell-activating factor belonging to the TNF family (BAFF)- $R$ is the principal BAFF receptor facilitating BAFF costimulation of circulating $\mathrm{T}$ and $\mathrm{B}$ cells. J Immunol 2004; 173: 807-17.

11. Schiemann B, Gommerman JL, Vora K, Cachero TG, Shulga-Morskaya S, Dobles M et al. An essential role for BAFF in the normal development of $B$ cells through a BCMA-independent pathway. Science 2001; 293: 2111-4.
12 Mackay F, Ambrose C. The TNF family members BAFF and APRIL: the growing complexity. Cytokine Growth Factor Rev 2003; 14: 311-24.

13 Nardem B, Belvedere O, Roschke V, Moore PA, Olsen HS, Migone TS et al. Synthesis and release of B-lymphocyte stimulator from myeloid cells. Blood 2001; 97: 198-204.

14 Scapini P, Nardem B, Nadali G, Calzetti F, Pizzolo G, Montecucco C ET AL. G-CSF-stimulated neutrophils are a prominent source of functional BLyS. J Exp Med 2003; 197: 297-302.

15 Ohata J, ZvalFer NJ, Nishio M, Boyie DL, Kaled SL, CARSON DA ET AL. Fibroblast-like synoviocytes of mesenchymal origin express functional B cell-activating factor of the TNF family in response to proinflammatory cytokines. J Immunol 2005; 174: 864-70.

16 Krumbholz M, Theil D, Derfuss T, Rosenwald A, Schrader F, Monoranu CM et al. BAFF is produced by astrocytes and up-regulated in multiple sclerosis lesions and primary central nervous system lymphoma. J Exp Med 2005; 201: 195-200.

17 Hase H, Kanno Y, Kojima M, Hasegawa K, Sakurai D, KojIMA H ET AL. BAFF/BLyS can potentiate B-cell selection with the B-cell coreceptor complex. Blood 2004; 103: 2257-65.

18 Zhang X, Park CS, Yoon SO, Lu L, Hsu YM, Ambrose C ET AL. BAFF supports human B cell differentiation in the lymphoid follicles through distinct receptors. Int Immunol 2005; 17: 779-88.

19 Gorelik L, Gilbride K, Dobles M, KaLed SL, Zandman Dscotт ML Normal B cell homeostasis requires B cell activation factor production by radiationresistant cells. J Exp Med 2003; 198: 937-45.

20 Nishio M, Endo T, Tsukada N, Ohata J, Kitada S, ReED JC ET AL. Nurselike cells express BAFF and APRIL, which can promote survival of chronic lymphocytic leukemia cells via a paracrine pathway distinct from that of SDF-1 alpha\}. Blood 2005.

21 Litinskiy MB, Nardew B, Hilbert DM, He B, SchafFer A, Casal P et al. DCs induce CD40-independent immunoglobulin class switching through BLyS and APRIL Nat Immunol 2002; 3: 822-9.

22 Craxton A, Magaletti D, Ryan Ejclark EA. Macrophage- and dendritic cell-dependent regulation of human B-cell proliferation requires the TNF family ligand BAFF. Blood 2003; 101: 4464-71.

23 Hanada T, Yoshida H, Kato S, TanaKa K, Masutani K, TsUKADA J ET AL. Suppressor of cytokine signaling-1 is essential for suppressing dendritic cell activation and systemic autoimmunity. Immunity 2003; 19: 437-50. 
24 SHu HB, Hu Whjohnson H. TAL-1 is a novel member of the TNF family that is down-regulated by mitogens. J Leukoc Biol 1999; 65: 680-3.

25 Novak AJ, Darce JR, Arendt BK, Harder B, Henderson K, Kindsvogel W et al Expression of BCMA, TACI, and BAFF-R in multiple myeloma: a mechanism for growth and survival. Blood 2004; 103: 689-94.

26 Thompson JS, Bixier SA, Qian F, Vora K, SCOTT ML, CACHERO TG ET AL. BAFF-R, a newly identified TNF receptor that specifically interacts with BAFF. Science 2001; 293: 2108-11.

27 Avery DT, Kaled SL, Euyyard JI, Ambrose C, Bixier SA, THIEN M ET AL. BAFF selectively enhances the survival of plasmablasts generated from human memory B cells. J Clin Invest 2003; 112: 286-97.

28 Tarte K, De Vos J, Thyjuaer T, Zhan F, Fiol G, Costes V ET AL. Generation of polyclonal plasmablasts from peripheral blood B cells: a normal counterpart of malignant plasmablasts. Blood 2002; 100: 1113-22.

29 Tarte K, Zhan F, De Vos J, Kifin B, Shaughnessy J Jr. Gene expression profiling of plasma cells and plasmablasts: toward a better understanding of the late stages of B-cell differentiation. Blood 2003; 102: 592-600.

30 Yan M, Brady JR, Chan B, Lee WP, Hsu B, Hariess S et AL. Identification of a novel receptor for B lymphocyte stimulator that is mutated in a mouse strain with severe B cell deficiency. Curr Biol 2001; 11: 1547-52.

31 Rahman ZS, Rao SP, KaLed Stmanser T. Normal induction but attenuated progression of germinal center responses in BAFF and BAFF-R signalingdeficient mice. J Exp Med 2003; 198: 1157-69.

32 Vora KA, Wang LC, Rao SP, Lu ZY, Majeau GR, Cutier AH ET AL. Cutting edge: germinal centers formed in the absence of B cell-activating factor belonging to the TNF family exhibit impaired maturation and function. J Immunol 2003; 171: 547-51.

33 Yan M, Marsters SA, Grewal IS, Wang H, Ashkenazi AdiXIT VM. Identification of a receptor for BLyS demonstrates a crucial role in humoral immunity. Nat Immunol 2000; 1: 37-41.

34 O'Connor BP, Raman VS, ERICKSon LD, Cook WJ, Weaver LK, Ahonen C et al. BCMA is essential for the survival of long-lived bone marrow plasma cells. J Exp Med 2004; 199: 91-8.

35 Seshasayee D, Vaidez P, Yan M, Dixit VM, Tumas D, GREWAL IS. Loss of TACI causes fatal lymphoproliferation and autoimmunity, establishing TACI as an inhibitory BLyS receptor. Immunity 2003; 18: 279-88.

36 Von Bulow GU, Van Deursen Jmbram RJ. Regulation of the T-independent humoral response by TACI.
Immunity 2001; 14: 573-82.

37 Yan M, Wang H, Chan B, Roose-Girma M, ERickson S, BAKER T ET AL. Activation and accumulation of B cells in TACI-deficient mice. Nat Immunol 2001; 2: 638-43.

38 Castigl E, Wilson SA, Garibyan L, Rachid R, Bonila F, SCHNEIDER L ET AL. TACI is mutant in common variable immunodeficiency and IgA deficiency. Nat Genet 2005; 37: 829-34.

39 Salzer U, Chapel HM, Webster AD, Pan-Hammarstrom Q, Schmitt-GraefF A, Schlesier M et al. Mutations in TNFRSF13B encoding TACI are associated with common variable immunodeficiency in humans. Nat Genet 2005; 37: 820-8.

40. GOLDACKER S, Warnatz K. Tackling the heterogeneity of CVID. Curr Opin Allergy Clin Immunol 2005; 5: 504-9.

41 SAIZER U, GRIMBACHER B. TACItly changing tunes: farewell to a yin and yang of BAFF receptor and TACI in humoral immunity? New genetic defects in common variable immunodeficiency. Curr Opin Allergy Clin Immunol 2005; 5: 496-503.

42 Gross JA, Johnston J, Mudri S, Enselman R, Diшon SR, MADDEN K ET AL. TACI and BCMA are receptors for a TNF homologue implicated in B-cell autoimmune disease. Nature 2000; 404: 995-9.

43 Gross JA, Dilon SR, Mudri S, Johnston J, Lttau A, ROQUE R ET AL. TACI-Ig neutralizes molecules critical for B cell development and autoimmune disease. impaired $\mathrm{B}$ cell maturation in mice lacking BLyS. Immunity 2001; 15: 289-302.

44 Cheema GS, Roschke V, Hilbert D, Stohl W. Elevated serum B lymphocyte stimulator levels in patients with systemic immune-based rheumatic diseases. Arthritis Rheum 2001; 44: 1313-9.

45 Tan SM, Xu D, Roschke V, Perry JW, Arkfeld DG, EHRESMANN GR ET AL. Local production of B lymphocyte stimulator protein and APRIL in arthritic joints of patients with inflammatory arthritis. Arthritis Rheum 2003; 48: 982-92.

46 Zhang J, Roschke V, Baker KP, Wang Z, Alarcon GS, FeSSLER BJ et al. Cutting edge: a role for B lymphocyte stimulator in systemic lupus erythematosus. J Immunol 2001; 166: 6-10.

47 Sтонц W. SLE-systemic lupus erythematosus: a BLySful, yet BAFFling, disorder. Arthritis Res Ther 2003; 5: 136-8.

48 Groom J, Kaled SL, Cutler AH, Olson C, WooDCOCK SA, SCHNEIDER P ET AL. Association of BAFF/ BLyS overexpression and altered B cell differentiation with Sjogren's syndrome. J Clin Invest 2002; 109: 59-68. 
49 Mariette X, Roux S, Zhang J, Bengoufa D, Lavie F, ZHOU T ET AL. The level of BLyS (BAFF) correlates with the titre of autoantibodies in human Sjogren's syndrome. Ann Rheum Dis 2003; 62: 168-71.

50 Briones J, Timmerman JM, Hilbert D, Levy R. BlyS and BLyS receptor expression in non-Hodgkin's lymphoma. Exp Hematol 2002; 30: 135-41.

51. Kern C, Cornuel JF, Bimard C, Tang R, Rouilard D, SteNOU V ET AL. Involvement of BAFF and APRIL in the resistance to apoptosis of B-CLL through an autocrine pathway. Blood 2004; 103: 679-88.

52 Moreaux J, Legouffe E, Jourdan E, Quittet P, Reme T, Lugagne C ET AL. BAFF and APRIL protect myeloma cells from apoptosis induced by interleukin 6 deprivation and dexamethasone. Blood 2004; 103: 3148-57.

$53 \mathrm{He}$ B, Chadburn A, Jou E, Schattner EJ, Knowles DMCERUTTI A. Lymphoma B cells evade apoptosis through the TNF family members BAFF/BLyS and APRIL J Immunol 2004; 172: 3268-79.

54 Stohl W, Cheema GS, Briggs WS, Xu D, Sosnovtseva S, RoschKE V ET AL B lymphocyte stimulator proteinassociated increase in circulating autoantibody levels may require CD4+ T cells: lessons from HIV-infected patients. Clin Immunol 2002; 104: 115-22.

55 Rodríguez B, Valdez $\mathrm{H}$, Freimuth W, Butler T, AsAad R, LEDERMAn MM. Plasma levels of Blymphocyte stimulator increase with HIV disease progression. Aids 2003; 17: 1983-5.

56 Moir S, Malaspina A, Pickeral OK, Donoghue ET, VAsquez J, MiLer NJ et al. Decreased survival of B cells of HIV-viremic patients mediated by altered expression of receptors of the TNF superfamily. J Exp Med 2004; 200: 587-99.

57 Muro-Cacho CA, Pantaleo G, Fauci AS. Analysis of apoptosis in lymph nodes of HIV-infected persons. Intensity of apoptosis correlates with the general state of activation of the lymphoid tissue and not with stage of disease or viral burden. J Immunol 1995; 154: 5555-66.

58 Samuelsson A, Sonnerborg A, HeUts N, Coster J, Chiodi F. Progressive B cell apoptosis and expression of Fas ligand during human immunodeficiency virus type 1 infection. AIDS Res Hum Retroviruses 1997; 13: 1031-8.

59 He B, Raab-Traub N, Casal P, Cerutti A. EBVencoded latent membrane protein 1 cooperates with BAFF/BLyS and APRIL to induce T cellindependent Ig heavy chain class switching. J Immunol 2003; 171: 5215-24.

60 KuPPERS R. B cells under influence: transformation of B cells by Epstein-Barr virus. Nat Rev Immunol 2003; 3: 801-12.

61 Baker KP, Edwards BM, Main SH, Choi GH, Wager RE, HALPERN WG ET AL. Generation and characterization of LymphoStat-B, a human monoclonal antibody that antagonizes the bioactivities of B lymphocyte stimulator. Arthritis Rheum 2003; 48: 3253-65.

62 Genovese MC. Biologic Therapies in Clinical Development for the Treatment of Rheumatoid Arthritis. J Clin Rheumatol 2005; 11: S45-54.

63 Sтонц W. A therapeutic role for BLyS antagonists. Lupus 2004; 13: 317-22.

64 Frye CA, Yocum DE, Tuan R, Suyana E, Seftor EA, SEFTor RE et al. An in vitro Model for Studying Mechanisms Underlying Synoviocyte-Mediated Cartilage Invasion in Rheumatoid Arthritis. Pathol Oncol Res 1996; 2: 157-166.

65 Lehmann J, Jungel A, Lehmann I, Busse F, BisKop M, SAALBACH A ET AL. Grafting of fibroblasts isolated from the synovial membrane of rheumatoid arthritis (RA) patients induces chronic arthritis in SCID mice-A novel model for studying the arthritogenic role of RA fibroblasts in vivo. J Autoimmun 2000; 15: 301-13.

66. Neidhart M, Seemayer CA, Hummel KM, Michel BA, GaY RegaY S. Functional characterization of adherent synovial fluid cells in rheumatoid arthritis: destructive potential in vitro and in vivo. Arthritis Rheum 2003; 48: 1873-80.

67 Pap T, Muler-Ladner U, Gay Regay S. Fibroblast biology. Role of synovial fibroblasts in the pathogenesis of rheumatoid arthritis. Arthritis Res 2000; 2: 361-7.

Agradecimientos

Financiado por Clínica Alemana Universidad del Desarrollo. 